\title{
Effect of aerosol and oral fenoterol on histamine and methacholine challenge in asthmatic subjects
}

\author{
CM SALOME, RE SCHOEFFEL, AJ WOOLCOCK
}

From the Department of Medicine, University of Sydney, and the Department of Thoracic Medicine, Royal Prince Alfred Hospital, Sydney, Australia

ABSTRACT In order to determine the effect of drugs on bronchial hyperreactivity in subjects with asthma, 12 atopic asthmatic volunteers underwent bronchial challenge with either histamine or methacholine on three separate days. Before the challenges no medication was given on the first day, on the second $400 \mu \mathrm{g}$ of aerosol fenoterol and on the third $5 \mathrm{mg}$ of oral fenoterol were administered. The aerosol fenoterol caused the dose response curves to both histamine and methacholine to be shifted to the right in all subjects. The oral dose produced no significant change from the control values. The slope of the dose response curves was not altered by either the oral or the aerosol drug. It is concluded that aerosol but not oral fenoterol in the clinical dosage, causes a change in the sensitivity but not in the reactivity of the airways of patients with atopic asthma.

Fenoterol, a $\beta_{2}$-adrenergic agonist has been shown in both oral and aerosol forms to be an effective bronchodilator. ${ }^{1-3}$ The aerosol form has been shown to protect against exercise-induced asthma (EJA) ${ }^{2}$ and to prevent early reactions to allergen challenge. ${ }^{3}$ Oral sympathomimetics appear to be less effective than aerosols in preventing EIA. ${ }^{2}{ }^{4}$ Cockcroft et al ${ }^{5}$ have shown that both inhaled and oral salbutamol will protect against histamine-induced bronchoconstriction, although the aerosol gives greater protection than the oral drug. This difference between oral and aerosol forms may reflect different tissue concentrations of the drug or may indicate that the mechanisms of bronchodilatation and of the prevention of induced bronchoconstriction are different. Orehek et $a l^{6}$ have distinguished two factors in the asthmatic reaction to bronchial challenge. Firstly, sensitivity which is the amount of a provoking agent required to produce a bronchoconstrictor response, and secondly reactivity, the way in which the airways respond to successive doses of the provoking agent. Their data suggest that it is the reactivity which best distinguishes asthmatic from non-asthmatic subjects. The cause of the heightened reactivity in asthma is unknown.

In order to study the factors which alter the degree of bronchial reactivity, a $\beta_{2}$-adrenergic agonist (fenoterol) was administered by aerosol and by

Address for reprint requests: Dr AJ Woolcock, Department of Medicine, University of Sydney, NSW 2006, Australia. mouth on different days, and the changes induced in sensitivity and reactivity to methacholine and histamine challenge were measured.

\section{Methods}

Twelve previously diagnosed atopic asthmatic volunteers, seven men and five women, aged between 19 and 38 years (mean 24 years) underwent bronchial challenge with either histamine diphosphate (Sigma Chemical Co, St Louis) or methacholine chloride (JT Baker Chemicals, NJ) on three separate days, at the same time of day. Eight were studied after both histamine and methacholine challenge. All medications were withheld for at least six hours before any challenge. Informed consent was obtained from each volunteer.

On the first day a bronchial challenge with 0 methacholine or histamine was performed using the $N$ standardised procedure described by Chai et al. ${ }^{7}$ Methacholine, in doubling concentrations from 0.075 $\mathrm{mg} / \mathrm{ml}$ to $50 \mathrm{mg} / \mathrm{ml}$, or histamine in doubling concentrations from $0.03 \mathrm{mg} / \mathrm{ml}$ to $10 \mathrm{mg} / \mathrm{ml}$, was delivered through a De Vilbiss No 646 nebuliser $\stackrel{5}{?}$ attached to a cylinder of medical air set at 20 psi. 7 The time of each nebulisation was controlled by a Dosimeter (Rosenthal-French, USA) set at $\mathbf{0 . 6}$ seconds. The subjects inhaled slowly from functional residual capacity (FRC) to total lung capacity (TLC) through a mouthpiece with the nose clamped.

Lung function was measured using a Vitalograph 
dry spirometer from which forced expiratory volume in one second $\left(F E V_{1}\right)$ and forced vital capacity (FVC) were recorded. For each subject, values were recorded initially and 90 seconds after each dose. The challenge began with five breaths of a saline control and continued with five breaths of each successive concentration of the provoking agent. The challenge was stopped when a $20 \%$ or greater fall in $\mathrm{FEV}_{1}$ was reached and maintained over three minutes. Spirometric function was measured at five, seven, 10 , and 15 minutes after completion of the challenge. All measurements were performed in duplicate or until reproducible values were obtained. Fenoterol aerosol was administered at the end of the test to ensure complete recovery from bronchoconstriction.

On the second day $400 \mu \mathrm{g}$ of aerosol fenoterol was administered by metred dose inhaler and 15 minutes later a challenge with histamine or methacholine was carried out. One and a half hours before challenge on the third day $5 \mathrm{mg}$ of oral fenoterol was administered.

Doses were recorded in inhalation units, as described by Chai et $a l^{7}$ where one unit equals one inhalation of a $1 \mathrm{mg} / \mathrm{ml}$ solution of either methacholine or histamine. Response was measured as the percent fall in $F E V_{1}$ from the pre-challenge value by the formula:

Percent fall FEV $1=$ $\frac{\text { post saline } \mathrm{FEV}_{1}-\text { post challenge } \mathrm{FEV}_{1}}{\text { post-saline } \mathrm{FEV}_{1}} \times 100$

Individual $\log$ dose response curves were plotted and the dose required to produce a $20 \%$ fall in $\mathrm{FEV}_{1}$ $\left(\mathrm{PD}_{20} \mathrm{FEV}_{1}\right)$ was recorded. In addition, doseresponse regression equations were calculated for the individual subjects from at least three points between the dose which initiated a consistent fall in $F \mathrm{FV}_{1}$ and the final dose. Correlation coefficients were calculated, and the regression equations were rejected when a significant correlation was not found. The coefficient " $a$ " from the formula, percent fall $\mathrm{FEV}_{1}=\mathrm{a} \log$ dose $+\mathrm{b}$, was recorded as a measure of the slope of the dose response curve.

Bronchodilator effect was recorded as percent rise in $\mathrm{FEV}_{1}$ from the formula:

Percent rise $\mathrm{FEV}_{1}=$

$$
\frac{\text { post dilator } \mathrm{FEV}_{1}-\text { pre-dilator } \mathrm{FEV}_{1}}{\text { pre-dilator } \mathrm{FEV}_{1}} \times
$$

Predicted values for FVC and $\mathrm{FEV}_{1}$ were taken from the data of Morris et al. ${ }^{8}$ Statistical comparison of the results was made using Student's $t$ tests of paired observations. Significance was taken at the $5 \%$ level.

Rate of recovery from challenge was analysed by performing regression analysis on the pooled data from all subjects at $1 \cdot 5,3,5,7,10$, and 15 minutes after challenge. Analysis of covariance was used to determine any differences between the three regimens in each study.

\section{Results}

Typical dose-response curves for one subject (NB) are shown in fig 1 . These were plotted for all subjects and the data obtained from them are presented in table 1 for histamine challenge and in table 2 for methacholine challenge. Both tables show the FEV results before the challenges, after no drug (C), after $5 \mathrm{mg}$ of oral fenoterol (O), and after $400 \mu \mathrm{g}$ of aerosol fenoterol (A) together with the $\mathbf{P D}_{20}$ and values for the slope of the curves. The mean values for $\mathbf{P D}_{20}$ are the geometric mean. It can be seen from the initial values for $\mathrm{FEV}_{1}$, which are expressed as a percentage of predicted values, that none of the subjects had severe airways obstruction before the challenge even on the control day, six hours after the last medication. The baseline $\mathrm{FEV}_{1}$, before challenge, was not different after the two forms of administration of the drug.

After aerosol fenoterol, the PD $_{20}$ for both histamine and methacholine was significantly higher than the
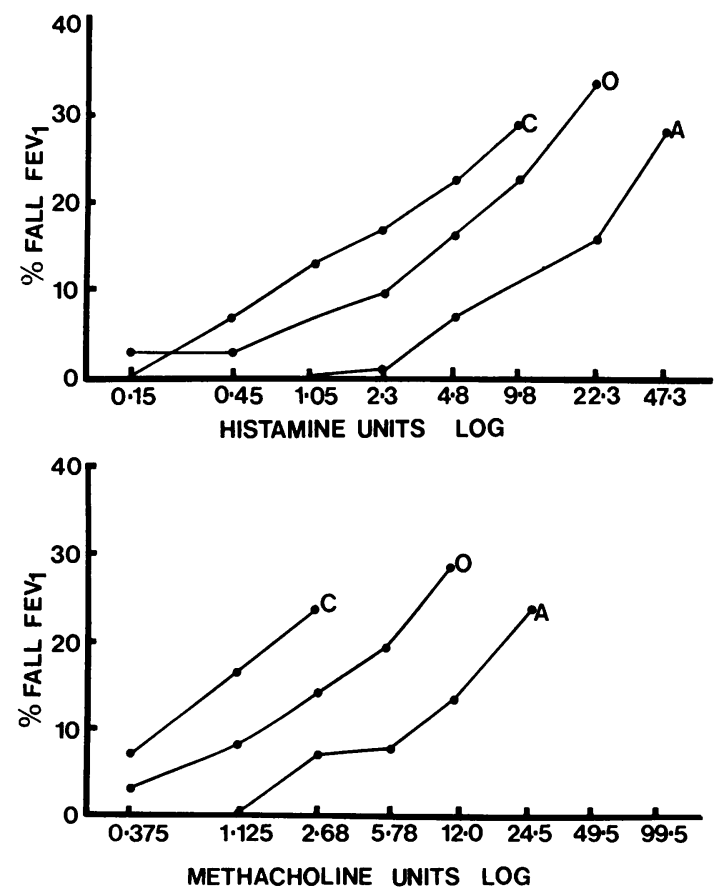

Fig 1 Dose-response curves to histamine and methacholine challenge in one subject. $C=$ challenge alone; $O=$ challenge after $5 \mathrm{mg}$ oral fenoterol; $A=$ challenge after $400 \mu \mathrm{g}$ aerosol fenoterol. 
Table 1 Dose-response curves to histamine challenge

\begin{tabular}{|c|c|c|c|c|c|c|c|c|c|c|c|}
\hline \multirow[t]{2}{*}{ Subject } & \multirow[t]{2}{*}{ Age $(y r)$} & \multirow[t]{2}{*}{ Sex } & \multicolumn{3}{|c|}{$\begin{array}{l}\text { Pre-challenge } F E V_{1} \\
(\% \text { predicted })\end{array}$} & \multicolumn{3}{|c|}{$\begin{array}{l}P D_{20} F E V_{1} \\
\text { (Inhalation dose units) }\end{array}$} & \multicolumn{3}{|l|}{ Slope } \\
\hline & & & $C$ & $O$ & $A$ & $C$ & $O$ & $A$ & $C$ & $O$ & $A$ \\
\hline $\mathrm{CE}$ & 29 & $\mathbf{F}$ & 113 & 117 & 126 & $6 \cdot 1$ & 26.0 & $>97 \cdot 3$ & $12 \cdot 2$ & $18 \cdot 5$ & - \\
\hline LM & 21 & $\mathbf{F}$ & 104 & 109 & 112 & $3 \cdot 4$ & $29 \cdot 0$ & $7 \cdot 0$ & 15.6 & 18.9 & $18 \cdot 8$ \\
\hline JE & 18 & $\mathbf{F}$ & 103 & 106 & 97 & $1 \cdot 2$ & $3 \cdot 5$ & $14 \cdot 3$ & $26 \cdot 1$ & 14.0 & 26.0 \\
\hline IJ & 20 & $\mathbf{M}$ & 89 & 83 & 89 & $9 \cdot 8$ & $10 \cdot 0$ & $>97.3$ & $28 \cdot 9$ & $33 \cdot 2$ & - \\
\hline DW & 19 & $\mathbf{M}$ & 90 & 109 & 116 & $2 \cdot 5$ & 6.8 & 38.0 & $21 \cdot 6$ & 42.9 & $34 \cdot 5$ \\
\hline $\mathbf{J M}$ & 22 & $\mathbf{M}$ & 63 & 92 & 99 & $12 \cdot 6$ & $11 \cdot 0$ & $97 \cdot 3$ & $24 \cdot 0$ & 10.4 & $27 \cdot 4$ \\
\hline NL & 21 & $\mathrm{~F}$ & 76 & 83 & 83 & $2 \cdot 4$ & 1.7 & $24 \cdot 0$ & $32 \cdot 4$ & $11 \cdot 3$ & $40 \cdot 1$ \\
\hline CB & 38 & $\mathbf{M}$ & 100 & 105 & 107 & $7 \cdot 9$ & $4 \cdot 4$ & $65 \cdot 0$ & $14 \cdot 7$ & $17 \cdot 2$ & $44 \cdot 6$ \\
\hline DA & 30 & $\mathbf{F}$ & 80 & 79 & 104 & $5 \cdot 6$ & $2 \cdot 7$ & $35 \cdot 5$ & $45 \cdot 4$ & $17 \cdot 5$ & $22 \cdot 2$ \\
\hline $\mathrm{AT}$ & 28 & $\mathbf{M}$ & 104 & 106 & 103 & $37 \cdot 0$ & $30 \cdot 0$ & $>97.3$ & $37 \cdot 8$ & $22 \cdot 1$ & - \\
\hline Mean & $24 \cdot 6$ & & $92 \cdot 2$ & 98.9 & 103.6 & +5.6 & $8 \cdot 1$ & $29 \cdot 7$ & 25.9 & 20.6 & 30.5 \\
\hline SEM & $2 \cdot 0$ & & $4 \cdot 9$ & $4 \cdot 2$ & $4 \cdot 0$ & 1.4 & $1 \cdot 4$ & 1.4 & $3 \cdot 4$ & $3 \cdot 2$ & 3.6 \\
\hline
\end{tabular}

†Geometric mean.

$\mathrm{C}=$ challenge alone, $\mathrm{O}=$ challenge after $5 \mathrm{mg}$ oral fenoterol, $\mathrm{A}=$ challenge after $400 \mu \mathrm{g}$ aerosol fenoterol.

Table 2 Dose-response curves to methacholine challenge

\begin{tabular}{|c|c|c|c|c|c|c|c|c|c|c|c|}
\hline \multirow[t]{2}{*}{ Subject } & \multirow[t]{2}{*}{ Age $(y r)$} & \multirow[t]{2}{*}{ Sex } & \multicolumn{3}{|c|}{$\begin{array}{l}\text { Pre-challenge } F E V_{1} \\
(\% \text { predicted })\end{array}$} & \multicolumn{3}{|c|}{$\begin{array}{l}P D_{20} F E V_{1} \\
\text { (Inhalation dose units) }\end{array}$} & \multicolumn{3}{|l|}{ Slope } \\
\hline & & & $C$ & $O$ & $A$ & $C$ & $O$ & $A$ & $C$ & $O$ & $A$ \\
\hline $\mathrm{CE}$ & 29 & $\mathbf{F}$ & 110 & 123 & 121 & $2 \cdot 6$ & $33 \cdot 0$ & $>475.0$ & $24 \cdot 6$ & $11 \cdot 2$ & - \\
\hline LM & 21 & $\mathbf{F}$ & 100 & 115 & 115 & 1.65 & $3 \cdot 8$ & $17 \cdot 5$ & $19 \cdot 7$ & $16 \cdot 8$ & 12.9 \\
\hline JE & 18 & $\mathbf{F}$ & 97 & 103 & 105 & 0.65 & $1 \cdot 8$ & 40.0 & $35 \cdot 7$ & $42 \cdot 5^{*}$ & $87 \cdot 2^{*}$ \\
\hline IJ & 20 & $\mathbf{M}$ & 89 & 91 & 95 & $3 \cdot 6$ & $18 \cdot 0$ & 110.0 & $21 \cdot 3$ & $12 \cdot 7$ & $23 \cdot 3$ \\
\hline DW & 19 & $\mathbf{M}$ & 107 & 113 & 114 & $2 \cdot 4$ & 16.0 & $16 \cdot 5$ & $28 \cdot 7$ & $28 \cdot 1$ & 19.0 \\
\hline JM & 22 & $\mathbf{M}$ & 80 & 93 & 100 & 10.0 & $11 \cdot 0$ & 50.0 & 16.0 & $16 \cdot 1$ & $34 \cdot 5$ \\
\hline NL & 21 & $\mathbf{F}$ & 78 & 79 & 83 & $1 \cdot 7$ & $2 \cdot 2$ & $30 \cdot 0$ & $36 \cdot 3^{*}$ & 19.9 & $37 \cdot 5^{*}$ \\
\hline CB & 38 & $\mathbf{M}$ & 84 & 96 & 113 & $3 \cdot 4$ & $4 \cdot 0$ & $32 \cdot 0$ & $42 \cdot 5^{*}$ & $24 \cdot 9$ & 25.6 \\
\hline RC & 20 & $\mathbf{M}$ & 70 & 79 & 83 & 40.0 & 39.0 & $260 \cdot 0$ & $9 \cdot 6$ & $13 \cdot 2$ & $8 \cdot 2$ \\
\hline DM & 19 & $\mathbf{M}$ & 103 & 108 & 107 & 1.9 & $9 \cdot 2$ & $>475.0$ & 20.9 & $15 \cdot 2$ & - \\
\hline Mean & $22 \cdot 7$ & & $91 \cdot 8$ & $100 \cdot 1$ & $102 \cdot 6$ & $\dagger 3 \cdot 2$ & $9 \cdot 0$ & $44 \cdot 7$ & $25 \cdot 5$ & $20 \cdot 1$ & $31 \cdot 1$ \\
\hline SEM & $2 \cdot 0$ & & $4 \cdot 3$ & $4 \cdot 8$ & $4 \cdot 0$ & 1.4 & 1.4 & $1 \cdot 4$ & $3 \cdot 2$ & $3 \cdot 0$ & $8 \cdot 7$ \\
\hline
\end{tabular}

Footnotes as in table 1.

*Correlation coefficient not significant.

$\mathrm{PD}_{20}$ for both the control study and the study after oral fenoterol ( $p<0.001$, in all cases). After oral fenoterol the $\mathbf{P D}_{20}$ was not significantly different from the control values for both challenges.

In some subjects aerosol fenoterol reduced the response to methacholine and histamine challenge so that the maximum challenge dose produced less than a $20 \%$ fall in $F E V_{1}$. In these subjects, $P_{20}$ was calculated as greater than the maximum doses (methacholine: 475 units, histamine: 97 units). No value for the slope of the dose-response curves could be calculated for these subjects. The correlation coefficients for the slope of the dose-response curves were significant in all subjects for histamine but for only seven subjects for methacholine (see table 2). For the three subjects without significant correlation coefficients estimated values for slope have been included in table 2 , but have not been included in the analysis.

In all instances where the correlation coefficients were significant, neither aerosol or oral fenoterol ? altered the slopes of the dose-response curves. In $N$ order to show the mean values for the change in $\underset{\mathrm{E}}{\mathcal{N}}$ position of the curves, the inhalational units causing 0 $10 \%$ and $20 \%$ changes in $\mathrm{FEV}_{1}$ for the histamine and methacholine challenges have been plotted in fig 2 .

Figure 3 shows the individual dose-response $\stackrel{\infty}{+}$ curves for histamine on the control day and after the 0 aerosol form of the drug. The hatched area indicates 0 the position on the dose-response curve which, in our $\stackrel{\mathbb{\Omega}}{\mathbb{D}}$ laboratory, separates people with current or recent $\mathbb{\mathbb { }}$ clinical asthma from normal people.

Bronchodilator therapy before the challenge did not affect the rate of recovery in the 15 minutes after 

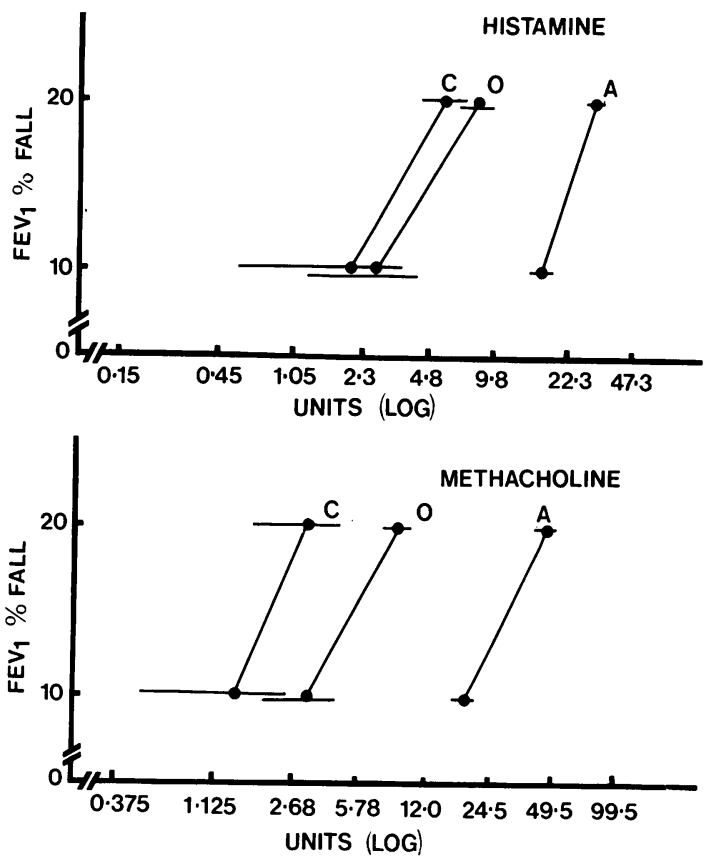

Fig 2 Geometric means for $P D_{10} F E V$ : and $P D_{20} F E V_{1}$ ( \pm standard error) for all subjects after histamine and methacholine challenge. $C=$ challenge alone $(n=10$ histamine and methacholine); $O=$ challenge after $5 \mathrm{mg}$ oral fenoterol ( $n=10$ histamine and methacholine); $A=$ challenge after $400 \mu \mathrm{g}$ aerosol fenoterol $(n=7$ histamine and 8 methacholine). the challenges. After histamine most subjects were within $13 \%$ and after methacholine within $21 \%$ of their initial values.

\section{Discussion}

This study shows that fenoterol administered by aerosol but not by mouth in normal clinical dosage, changes the position of the dose-response curve (reduces the sensitivity) of asthmatic subjects to histamine and methacholine. In these subjects, neither aerosol nor oral fenoterol had an effect on the slope of the dose-response curve (that is the reactivity) to histamine or methacholine.

The design of the study was kept simple and was not done in a double-blind manner because, during previous studies, we have found that subjects invariably know when the active drug has been given. Each subject was simply told that the study was to determine the effect of the drug on his response to bronchial provocation. It was never suggested that one form of administration might have a different effect from the other form.

Juniper et $a l^{9}$ have shown that sensitivity to both histamine and methacholine is highly reproducible in asthmatic subjects. Reactivity is a more variable measurement and is difficult to determine accurately using the present method since several points on the linear part of the curve must be documented. A significant correlation coefficient for the dose response in all subjects given methacholine would probably have been achieved if the doses had been

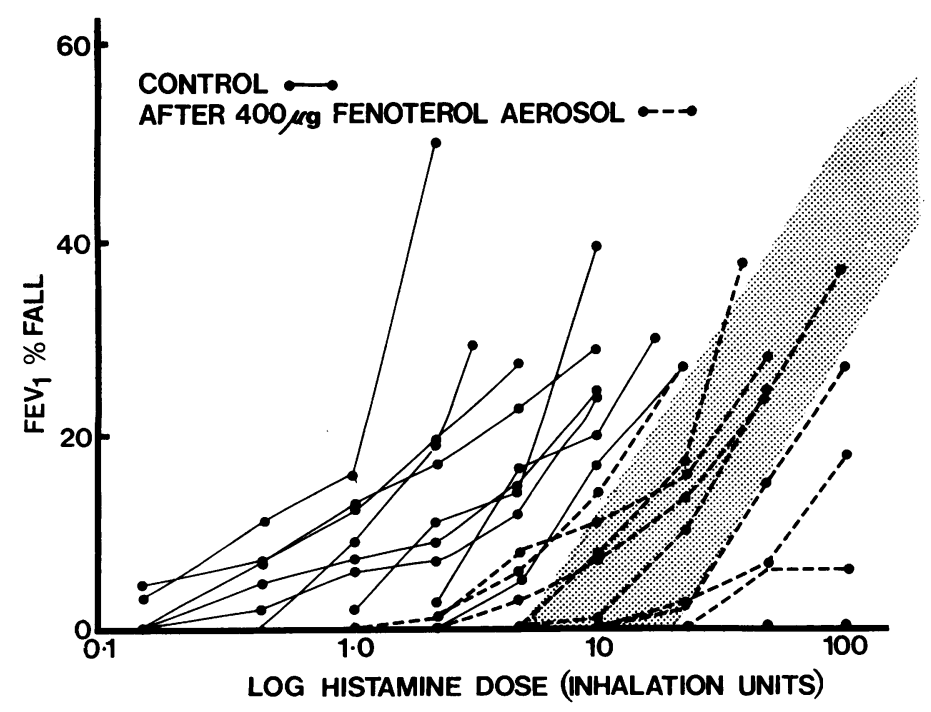

Fig 3 Individual dose-response curves to histamine challenge alone and after 400 $\mu \mathrm{g}$ aerosol fenoterol. For an explanation of the hatched area, see text. 
increased more gradually. However, even in these three subjects, the slope was obviously not changed by the drugs.

It appears that the effect of aerosol fenoterol is to shift the dose-response curve to the right, without altering its shape. This confirms the finding of Cockcroft et al ${ }^{5}$ who showed that the effect of $\beta_{2}$ aerosols was to change the position of the doseresponse curve of asthmatic patients to bronchial challenge with histamine, although they did not measure the slope. This study has shown that the effect is produced by simply increasing the threshold of the asthmatic response without changing the slope. Figure 3 shows the individual results for the histamine challenge. In our experience, subjects whose dose-response curves fall in the shaded area have very mild asthma with infrequent attacks and require little therapy. The dose-response curves of all but two subjects were shifted into this range and two were clearly in the normal range in which it would be unlikely for a spontaneous attack of asthma to occur. Further studies are needed to determine if larger doses of fenoterol shift the doseresponse curve even further to the right and for how long the drug is effective in maintaining the shift.

The inability of the oral $\beta_{2}$ agonists to protect against induced bronchoconstriction has been noted by other workers ${ }^{3} 5$ and is confirmed by this study for this particular dose. This difference between aerosol and oral forms of the drug may simply reflect differences in local concentration but it is possible that $\beta_{2}$ agonists act on more than one site in the airway. Their action on the $\beta_{2}$ adrenoreceptors of the smooth muscle is well known. In addition, they may act on a number of structures in the mucosa including mast cells, the irritant nerve endings, or epithelial tight junctions. Since the mechanisms by which histamine and methacholine cause airway narrowing in asthmatic subjects are not understood, it is not possible to determine which of these structures may be affected by the drug.

For purposes of treatment, the greater ability of the aerosol fenoterol to protect against induced bronchoconstriction suggests that $\beta_{2}$ agonists in small dosage on or near the surface of the airways can decrease sensitivity and perhaps protect against a number of provoking stimuli occurring in everyday life. In other words, it appears to shift the response of the airways temporarily from the asthmatic into the $\frac{\overline{0}}{-}$ non-asthmatic range. Perhaps future drugs being $\overline{\overline{0}}$ investigated for the treatment of asthma could be $\overline{\mathrm{Q}}$ studied both for their bronchodilating effect and their ability to protect against provoked attacks. As ${ }^{\mathrm{C}}$ yet no drug has been shown to alter reactivity as $\vec{O}$ opposed to sensitivity in asthmatic subjects. Further $\vec{\overrightarrow{ }}$ studies of the effect of increasing doses of the aerosol and of the duration of its "protective" action are $\vec{f}$ needed. Tailor-made therapy, to find the dose and ${ }_{\omega}^{x}$ frequency of bronchodilator aerosol administration. which keeps asthmatic subjects in the non-asthmatic ${ }^{\infty}$ range, might be a logical method of treatment, particularly for subjects with severe disease.

This study was supported by the National Health and Medical Research Council and the Asthmac Foundation of New South Wales.

\section{References}

1 Van Ardsel PP Jr, Schaffrin RM, Rosenblatt J, Sprenkle AC, Alfman LC. Evaluation of oral fenoterol in chronic asthmatic patients. Chest 1978;73:997-8.

2 Anderson SD, Rozea PJ, Dolton R, Lindsay DA. Inhaledڤ̆ and oral bronchodilator therapy in exercise induced asthma. Aust $N Z J$ Med 1975;5:544-50.

${ }^{3}$ Booij-Noord H, Quanjer PH, de Vries K. Protective effectō of Berotec in provocation tests using inhalation of 3 specific allergens and histamine. Int $J$ Clin Pharmaco $P$ Ther Toxicol, (Suppl) 1972;4:69-72.

4 Anderson SD, Seale JP, Rozea P, Bandler L, Theobald G, Linsday DA. Inhaled and oral salbutamol in exercise induced asthma. Am Rev Respir Dis 1976;114:493-500.

${ }^{5}$ Cockcroft DW, Killian DN, Mellon JJA, Hargreave FE. $\stackrel{\mathfrak{x}}{\sim}$ Protective effects of drugs on histamine-inducedo asthma. Thorax 1977;32:429-37.

- Orehek J, Gayrard P, Smith AP, Grimaud C, Charpin J.' Airway response to carbachol in normal and asthmatic윽 subjects. Distinction between bronchial sensitivity and reactivity. Am Rev Respir Dis 1977;115:937-43.

7 Chai H, Farr RS, Froelich LA et al. Standardisation of bronchial inhalation challenge procedures. J Allergy Clino Immunol 1975;56:323-7.

${ }^{8}$ Morris JF, Koski A, Johnson LC. Spirometric standardsN for healthy non-smoking adults. Am Rev Respir Dis. 1971;103:57-67.

9 Juniper EF, Frith PA, Dunnett C, Cockcroft DW, 응 Hargreave FE. Reproducibility and comparison of responses to inhaled histamine and methacholine $\underset{<}{ }$ Thorax 1978;33:705-10. 